\title{
Antitumor Agents. 271. Total Synthesis and Evaluation of Brazilein and Analogs as Anti-inflammatory and Cytotoxic Agents
}

\author{
Chiao-Ting Yen ${ }^{\mathrm{a}, \mathrm{b}}$, Kyoko Nakagawa-Goto ${ }^{\mathrm{a}}$, Tsong-Long Hwang ${ }^{\mathrm{C}}$, Pei-Chi Wua ${ }^{\mathrm{a}}$, Susan L. \\ Morris-Natschke ${ }^{a}$, Wan-Chun Lai ${ }^{b}$, Kenneth F. Bastow ${ }^{d}$, Fang-Rong Chang ${ }^{b}$, Yang-Chang \\ $\mathrm{Wu}^{*}, \mathrm{~b}, \mathrm{e}$, and Kuo-Hsiung Lee ${ }^{*}, \mathrm{a}$ \\ aNatural Products Research Laboratories, UNC Eshelman School of Pharmacy, University of North \\ Carolina at Chapel Hill, NC 27599-7568, USA \\ ${ }^{b}$ Graduate Institute of Natural Products, Kaohsiung Medical University, Kaohsiung 807, Taiwan \\ 'Graduate Institute of Natural Products, Chang Gung University, Tao-Yuan 333, Taiwan \\ dDivision of Medicinal Chemistry and Natural Products, UNC Eshelman School of Pharmacy, \\ University of North Carolina, Chapel Hill, NC 27599-7568, USA
}

e'Center of Excellence for Environmental Medicine, Kaohsiung Medical University, Kaohsiung 807, Taiwan

\begin{abstract}
The first total synthesis of the naturally occurring tetracyclic homoisoflavonoid brazilein (1) and 14 new analogs (1a-n) is reported. Target compounds and intermediates were assayed for antiinflammatory effects on superoxide anion generation and elastase release by human neutrophils in response to fMLP/CB, and for cytotoxic activity against nasopharyngeal (KB), vincristine-resistant nasopharyngeal (KBvin), lung (A549) and prostate (DU-145) human cancer cell lines. The most active compound $\mathbf{1 b}$ showed potent effects on superoxide anion generation and elastase release with $\mathrm{IC}_{50}$ values of 1.2 and $1.9 \mu \mathrm{M}$, respectively, and was 65 times more potent than phenylmethylsulfonyl fluoride (PMSF), the positive control, in the latter assay. Additionally, $\mathbf{1 b}$ exhibited broad spectrum in vitro anticancer activity with $\mathrm{IC}_{50}$ values of 6-11 $\mu \mathrm{M}$ against the four tested cancer cell lines.
\end{abstract}

\section{Keywords}

homoisoflavonoid; brazilein; anti-inflammatory; cytotoxic

\begin{abstract}
Naturally occurring homoisoflavonoids (3-benzylidene-4-chromanones) are related structurally to flavonoids, and exhibit various biological activities. ${ }^{1}$ Synthesis of the 3benzylidene-4-chromanone skeleton is usually based on the condensation of 4-chromanones with aromatic aldehydes in the presence of an acidic or basic catalyst.2.3 Although members of this family have been the subjects of several syntheses, 4,5 there are no reports on the total synthesis of brazilein (1) nor the preparation of $\mathbf{1}$-analogs.
\end{abstract}

\footnotetext{
(C) 2009 Elsevier Ltd. All rights reserved.

*Corresponding authors. Tel.: (+886)-7-312-1101 ext. 2197; fax: (+886)-7-311-4773 (Y.C.W.); Tel.: (+1)-919-0962-0066; fax: (+1)-919-966-3893 (K.H.L.). yachwu@kmu.edu.tw (Y. C. Wu), khlee@unc.edu (K. H. Lee).

Publisher's Disclaimer: This is a PDF file of an unedited manuscript that has been accepted for publication. As a service to our customers we are providing this early version of the manuscript. The manuscript will undergo copyediting, typesetting, and review of the resulting proof before it is published in its final citable form. Please note that during the production process errors may be discovered which could affect the content, and all legal disclaimers that apply to the journal pertain.
} 
In our prior study, we isolated the unique tetracyclic homoisoflavonoid brazilein (1), whose stereochemistry was obtained as dextrorotatory, ${ }^{6}$ from an ethyl acetate extract of Caesalpinia sappan L. (Legminosae). Brazilein ( $(6 \mathrm{a} R)$-6a,7-dihydro-3,6a,10-trihydro-benz[ $b]$ indeno[1,2d] pyran-9-(6H)-one) is a natural red pigment used in traditional Chinese medicine. It also exhibits significant cytotoxic activity against HepG2 and Hep3B (liver), MDA-MB-231 and MCF-7 (breast), A549 (lung) and Ca9-22 (gingival) human cancer cell lines (Table 1). ${ }^{6} \mathrm{~b}$ Previous literatures showed that brazilein (1) exhibited immunosuppressive activity in mice lymphocytes, ${ }^{7}$ cardiotonic effects in isolated rat hearts, ${ }^{8}$ and anti-oxidant properties. ${ }^{9,10}$ Brazilin (2) is the hydrogenation product of brazilein (1) in the proposed biosynthetic route, 11 and can be oxidized to brazilein (1) when the extract has been exposed to air and light. Beyond this redox chemistry, our interest in devising a general synthesis for this skeleton was based on literature reports that brazilin (2) has cytotoxicity (Table 1) ${ }^{6}$ and anti-inflammatory properties, ${ }^{12,13}$ acts as a micromolar telomerase inhibitor, ${ }^{14}$ and produces DNA nicks. ${ }^{15}$ These properties are often associated with useful anticancer agents. Additionally, to the best of our knowledge, brazilein (1) and its derivatives have not been studied for anti-inflammatory and cytotoxic effects. Considering the structural similarities between brazilin (2) and brazilein (1), we wanted to determine whether the latter exhibits a similar spectrum of in vitro antiinflammatory and anticancer effects.

We report herein a strategy that enables the preparation of $\mathbf{1}$ by construction of the benzylidene moiety via acid- or base-catalyzed aldol condensation with aryl aldehydes. All newly synthesized compounds, including structurally related intermediates, were assayed for in vitro cytotoxicity against four human cancer cell lines, [KB (nasopharngeal), KBvin (multidrug-resistant nasopharngeal over-expressing P-gp), A549 (lung) and DU-145 (prostate)] and for anti-inflammatory action in terms of superoxide anion generation and elastase release by human neutrophils in response to fMLP/CB.

The general synthesis of brazilein (1) was achieved through the route outlined in Scheme 1. 7Hydroxy-4-chromanone (5), a key intermediate, was readily obtained by reaction of resorcinol (3) and 3-chloropropionic acid promoted by trifluoromethanesulfonic acid to give 2',4'dihydroxy-3-chloropropiophenone (4), which was further cyclized using $2 \mathrm{M} \mathrm{NaOH}^{16}$ to give 5 in 78\% yield. Treatment of 5 with iodomethane in the presence of $\mathrm{K}_{2} \mathrm{CO}_{3}$ /acetone gave $\mathbf{6}$ $(60 \%)$. Acid catalyzed ${ }^{17}$ condensation of 6 with 3,4-dimethoxybenzaldehyde afforded 7 (78\%). Epoxidation of 7 with alkaline hydrogen peroxide gave epoxy ketone 8 (90\%), which was reduced to the diol 9 (89\%) with $\mathrm{LiAlH}_{4} \cdot{ }^{3}$ Cyclization to the desired product was affected by $\mathrm{HClO}_{4}{ }^{3}$ to yield trimethylbrazilin $\mathbf{1 0}$ in $31 \%$ yield. Compound $\mathbf{1 0}$ was demethylated using pyridine hydrochloride ${ }^{18}$ to give 2 in $36 \%$ yield. Brazilin (2) was oxidized with a catalytic amount of iodine solution to give brazilein (1) in $78 \%$ yield.

In addition, the brazilein derivatives $\mathbf{1 a}, \mathbf{1 b} / \mathbf{c}$, and $\mathbf{1 d}$ were obtained by esterification of $\mathbf{1}$ with acetic anhydride, propionyl chloride, and benzoic chloride, respectively, in pyridine. For $\mathbf{1 e}$ and $\mathbf{1 f}, \mathbf{1}$ was reacted in strong base $(\mathrm{NaH})$ with dimethylcarbamyl chloride and diethylcarbamyl chloride to produce the desired products $\mathbf{1 d}$ and $\mathbf{1 f}$, respectively. Compounds $\mathbf{1 g}-\mathbf{n}$ were synthesized by the general Williamson method as described in previous reports. ${ }^{19,20}$ Specifically, $\mathbf{1 g}-\mathbf{n}$ were prepared by alkylation of $\mathbf{1}$ with iodomethane (1g and $\left.\mathbf{h}\right)$,

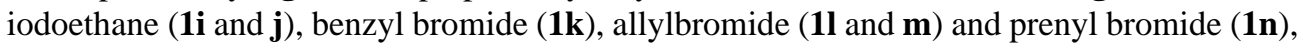
in the presence of $\mathrm{K}_{2} \mathrm{CO}_{3}$ in acetone. Accordingly, the first total syntheses of $\mathbf{1}$ and 14 analogs (1a-n) (Figure 1) were accomplished.

\section{Anti-inflammatory activity}

Synthesized 1, 2, and intermediates 7-10 together with analogs 1a-n, which are divided into three classes based on the substitution pattern at C-3, C-6a and C-10 and functionalized into 
ester, carbamate and ether, were evaluated for anti-inflammatory action based on effects against superoxide anion generation and elastase release by human neutrophils in response to fMLP/ $\mathrm{CB}$. The assays were performed using established protocols, ${ }^{21,22}$ which are widely used to identify potential anti-inflammatory compounds. Table 2 lists the results for the test compounds, as well as diphenyleneiodonium (DPI) and phenylmethylsulfonyl fluoride (PMSF), included as positive controls for superoxide anion generation and elastase release, respectively. Results are expressed as the mean \pm S.E.M., and comparisons were made using Student's $t$-test. A probability of 0.05 or less was considered significant.

Among the esterified compounds 1a-d, analogs 1a (di-acetate) and 1d (tri-benzoate) showed selective anti-inflammatory activity (1a $v s$ superoxide anion generation, $18.7 \mu \mathrm{M} ; \mathbf{1 d} v s$ elastase release, $13.3 \mu \mathrm{M}$ ). Analog $\mathbf{1 b}$ (tri-proprionate) showed the highest potency against both superoxide anion generation and elastase release with significant $\mathrm{IC}_{50}$ values of 1.2 and $1.9 \mu \mathrm{M}$, respectively. Analog 1c (di-propionate) was slightly less potent with $\mathrm{IC}_{50}$ values of 1.65 and $3.28 \mu \mathrm{M}$, but still was more active than the parent compound $\mathbf{1}$. Therefore, replacing the hydroxy groups with propionate esters increased potency in both assays, particularly when all three hydroxyls were esterified in $\mathbf{1 b}$.

$N$-Diethyl carbamate $\mathbf{1 f}$ showed a weak effect $\left(\mathrm{IC}_{50} 15.5 \mu \mathrm{M}\right)$ in response to fMLP/CB-induced elastase release, but neither 1 f nor the $N$-dimethyl carbamate 1e showed a significant effect against superoxide anion generation. Although the ester and carbamate functional group present parallel physical and chemical properties, the data showed that the former did provide better activity against either superoxide anion generation or elastase release.

Among the eight compounds (1g-n) containing ether substituents, $\mathbf{1 g}$ (tri-methoxy) and $\mathbf{1 j}$ (diethoxy) displayed potent effects in the superoxide anion assay $\left(\mathrm{IC}_{50} 4.7\right.$ and $4.4 \mu \mathrm{M}$, respectively). Analog $\mathbf{1 j}$ (di-ethoxy) also showed a moderate effect $\left(\mathrm{IC}_{50} 8.4 \mu \mathrm{M}\right)$ against elastase release, as did 1k (di-benzoxy) ( $\mathrm{IC}_{50} 8.8 \mu \mathrm{M}$ ). Compounds $\mathbf{1 1 - n}$ (allyl and prenyl ethers) were non-selective, but with only weak inhibitory effects in both assays ( $\mathrm{IC}_{50}$ 10-20 $\mu \mathrm{M})$. These findings suggest that $\mathbf{1 g}$ and $\mathbf{1} \mathbf{j}$ merit further investigation as potential antiinflammatory compounds.

Furthermore, among the synthetic intermediates 7-10 (Table 1), the epoxy ketone 8 was significantly potent and selective $\left(\mathrm{IC}_{50} 1.9 \mu \mathrm{M}\right)$ against superoxide anion generation. The diol 9 was moderately active in both anti-inflammatory assays $\left(\mathrm{IC}_{50} 8.4\right.$ and $\left.10.3 \mu \mathrm{M}\right)$, while the tetracyclic 10 was potent only against superoxide anion generation $\left(\mathrm{IC}_{50} 4.5 \mu \mathrm{M}\right)$.

In conclusion, among all screened compounds, including ester (1a-d), carbamate (1e and 1f), and ether (1g-n) derivatives, the preliminary structure-activity relationship were addressed in the order: a) ester > ether > carbamate; b) ethyl $\fallingdotseq$ methyl > allyl $\fallingdotseq$ prenyl $>$ benzyl. In particular, the most potent analog $\mathbf{1 b}$ was 65 -fold more active than PMSF, the positive control, in the elastase release assay.

\section{Anti-cancer activity}

The homoisoflavonoids 1a-n as well as the synthesized 1, 2 and intermediates 7-10 were examined for in vitro cytotoxic activity against four human cancer lines. Table 3 lists the $\mathrm{IC}_{50}$ values obtained with test compounds compared to the anticancer drug paclitaxel as a positive control. Among the 14 derivatives $(\mathbf{1 a - n})$, seven compounds $(\mathbf{1 a}-\mathbf{c}, \mathbf{1 g}, \mathbf{1 i}, \mathbf{1 j}$ and 1m) showed moderate potency against the tested human cancer cell lines with $\mathrm{IC}_{50}$ values of 5-18 $\mu \mathrm{M}$; however, they all were much less active than paclitaxel.

In our previous study, the parent compound $\mathbf{1}$ showed moderate cytotoxic activity against six cancer cell lines $\left(\mathrm{IC}_{50} 8-34 \mu \mathrm{M}\right.$, Table 1$) .{ }^{6 \mathrm{~b}}$ Comparison of 1 to its synthetic intermediates 2 
and 7-10 showed that the epoxy ketone $\mathbf{8}$ had comparable or enhanced activity, while the reduced diol 9 was inactive $\left(\mathrm{IC}_{50}>20 \mu \mathrm{M}\right)$. In addition, trimethylbrazilin 10 was more active than 2 with $\mathrm{IC}_{50}$ values of $10-15 \mu \mathrm{M}$ against all four human cancer cell lines. The enhanced cytotoxicity of epoxide analog $\mathbf{8}$ could account for its twofold greater potency than $\mathbf{1}$ against superoxide anion generation.

\section{Acknowledgments}

This investigation was supported by a grant CA 17625 from National Cancer Institute, NIH, USA (K. H. Lee), and by the National Science Council, Taiwan (Y.-C. Wu) and KMU-EM-97-2.1.b (Y.-C. Wu).

\section{References and notes}

1. Lockhart, IM. The Chemistry of Heterocylic Compounds; Chromenes, Chromanones and Chromones. Ellis, GP., editor. New York: John Wiley \& Sons; 1977.

2. Malhotra S, Sharma VK, Parmar VS. J. Chem. Res. (S) 1988:179.

3. Farkas L, Gottsegen A, Norgradi M. Tetrahedron 1970;26:2787.

4. Huang YD, Zhang J, Pettus T. Org. Lett 2005;26:5841. [PubMed: 16354080]

5. Davis F, Chen BC. J. Org. Chem 1993;58:1751.

6. (a) Kim DS, Baek NI, Oh SR, Jung KY, Lee IS, Lee HK. Phytochemistry 1997;46:177.(b) Lai, WC. Master Thesis. Kaohsiung Medical University; 2007 Jul.

7. Ye M, Xie WD, Lei F, Meng Z, Zhao YN, Su H, Du LJ. Int. Immunopharmacol 2006;6:426. [PubMed: 16428078]

8. Zhao YN, Pan Y, Tao JL, Xing DM, Du LJ. Pharmacology 2006;76:76. [PubMed: 16319518]

9. Kabbash A, Yagi A, Ishizu T, Haraguchi H, Fujioka T, Moustafa SM, El-Bassuony Ashraf A. Saudi Pharm. J 2008;16:25.

10. Hu, Jun; Yan, Xiaoling; Wang, Wei; Wu, Hao; Hua, Lei; Du. Lijun. Tsinghua Sci. Technol 2008; $13: 474$.

11. Hikino H, Taguchi T, Fujimura H, Hiramatsu Y. Planta Med 1977;31:214. [PubMed: 866477]

12. Bae IK, Min HY, Han AR, Seo EK, Lee SK. Eur. J. Pharmacol 2005;513:237. [PubMed: 15862806]

13. Nagai M, Nagumo S, Lee SM, Eguchi I, Kawai KI. Chem. Pharm. Bull 1986;34:1.

14. Tolman, RL.; Chin, ACWO. Patent. 0,193,864. 2001 Dec 13.

15. Mar W, Lee HT, Je KH, Choi HY, Seo EK. Arch. Pharm. Res 2003;26:147. [PubMed: 12643592]

16. Namikoshi M, Nakata H, Yamada H, Nagai M, Saitoh T. Chem. Pharm. Bull 1987;35:2761.

17. Venkateswarlu S, Panchanula GP, Guraiah MB, Subbaraju GV. Tetrahedron 2005;61:3013.

18. Siddaiah V, Rao CV, Venkateswarlu S, Krishnaraju AV, Subbaraju GV. Bioorg. Med. Chem 2006;14:2545. [PubMed: 16337386]

19. Gao GY, Li DJ, Keung WM. Bioorg. Med. Chem 2003;11:4069. [PubMed: 12927869]

20. Hosoda S, Hashimoto Y. Bioorg. Med. Chem. Lett 2007;17:5414. [PubMed: 17686629]

21. Chang HL, Chang FR, Chen JS, Wang HP, Wu YH, Wang CC, Wu YC, Hwang TL. Eur. J. Pharmacol 2008;586:332. [PubMed: 18367166]

22. Hwang TL, Yeh SH, Leu YL, Chern CY, Hsu HC. Br. J. Pharmacol 2006;148:78. [PubMed: 16501579] 


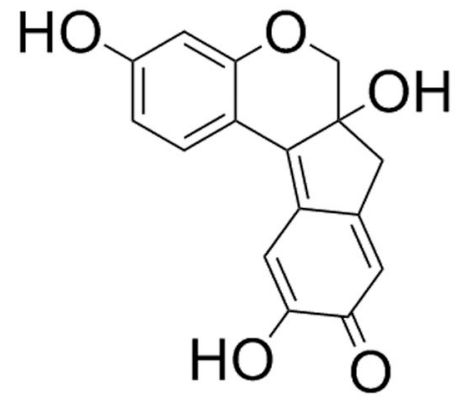

1, Brazilein

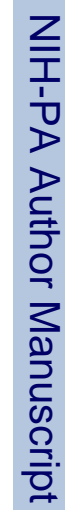

Figure 1.<smiles>Oc1ccc2c(c1)OCC1(O)Cc3cc(O)c(O)cc3C21</smiles>

2, Brazilin

$$
\mathrm{R}^{1}=\mathrm{R}^{2} \quad \mathrm{R}^{3}
$$

1a $\mathrm{COCH}_{3} \quad \mathrm{H}$

1b $\mathrm{COCH}_{2} \mathrm{CH}_{3} \quad \mathrm{COCH}_{2} \mathrm{CH}_{3}$

1c $\mathrm{COCH}_{2} \mathrm{CH}_{3} \quad \mathrm{H}$

1d $\mathrm{COC}_{6} \mathrm{H}_{5} \quad \mathrm{COC}_{6} \mathrm{H}_{5}$

1e $\mathrm{CON}\left(\mathrm{CH}_{3}\right)_{2} \quad \mathrm{H}$

1f $\mathrm{CON}\left(\mathrm{CH}_{2} \mathrm{CH}_{3}\right)_{2} \quad \mathrm{H}$

$1 \mathrm{~g} \mathrm{CH}_{3}$

1h $\mathrm{CH}_{3}$

1i $\mathrm{CH}_{2} \mathrm{CH}_{3}$

1j $\mathrm{CH}_{2} \mathrm{CH}_{3}$

1k $\mathrm{CH}_{2} \mathrm{C}_{6} \mathrm{H}_{5}$

1I $\mathrm{CH}_{2} \mathrm{CH}=\mathrm{CH}_{2}$

$1 \mathrm{~m} \mathrm{CH}_{2} \mathrm{CH}=\mathrm{CH}_{2}$

$\mathrm{CH}_{3}$

$\mathrm{H}$

$\mathrm{CH}_{2} \mathrm{CH}_{3}$

$\mathrm{H}$

$\mathrm{H}$

$\mathrm{CH}_{2} \mathrm{CH}=\mathrm{CH}_{2}$

1n $\mathrm{CH}_{2} \mathrm{CH}=\mathrm{C}\left(\mathrm{CH}_{3}\right)_{2} \mathrm{H}$

Molecular structures of brazilein (1), brazilin (2) and synthetic 1-analogs. 
<smiles>COc1ccc2c(c1)OCCC2=O</smiles><smiles>COc1ccc2c(c1)OCC(=Cc1ccc(OC)c(OC)c1)C2=O</smiles><smiles></smiles>

Scheme 1.

Total synthesis of brazilein (1).

Reagents: (a) 3-Chloropropionic acid, $\mathrm{CF}_{3} \mathrm{SO}_{3} \mathrm{H}, 80{ }^{\circ} \mathrm{C}, 1 \mathrm{~h}, 92 \%$; (b) $2 \mathrm{M} \mathrm{NaOH}, 0{ }^{\circ} \mathrm{C}, 2 \mathrm{~h}$, $78 \%$; (c) Iodomethane, $\mathrm{K}_{2} \mathrm{CO}_{3}$, acetone, $60{ }^{\circ} \mathrm{C}, 5 \mathrm{~h}, 60 \%$; (d) 3,4-Dimethoxylbenzaldehyde, EtOH, $\mathrm{HCl}$ gas, rt, overnight, 78\%; (e) $\mathrm{H}_{2} \mathrm{O}_{2}$, dioxane, rt, 24h, 90\%; (f) $\mathrm{LiAlH}_{4}$, THF, rt, overnight, $89 \%$; (g) $\mathrm{HClO}_{4}$, acetic acid, rt, overnight, $31 \%$; (h) Pyridine- $\mathrm{HCl}, 190-200{ }^{\circ} \mathrm{C}, 3 \mathrm{~h}$, $36 \%$; (i) $1 \mathrm{~N} \mathrm{I}_{2(\mathrm{aq})}$, rt, overnight, $78 \%$. 


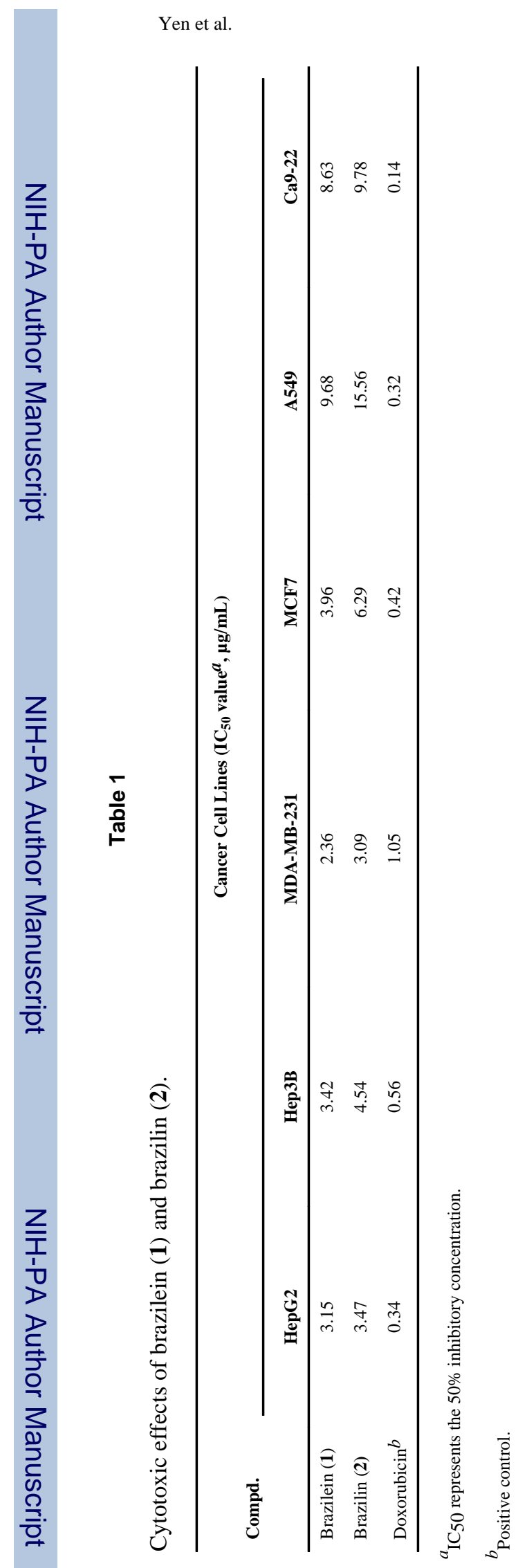

Page 7 
Table 2

Inhibitory effects of compounds on superoxide anion generation and elastase release by human neutrophils in response to FMLP/CB.

\begin{tabular}{|c|c|c|}
\hline \multirow{2}{*}{ Compound } & \multirow{2}{*}{$\begin{array}{l}\text { Superoxide anion } \\
\mathrm{IC}_{50}(\mu \mathrm{M})^{a} \text { or }(\operatorname{Inh} \%) \\
\end{array}$} & \multirow{2}{*}{$\begin{array}{l}\text { Elastase release } \\
\mathrm{IC}_{50}(\mu \mathrm{M}){ }^{a} \text { or }(\operatorname{Inh} \%)\end{array}$} \\
\hline & & \\
\hline Brazilein (1) & $4.0 \pm 0.42$ & $14.2 \pm 1.32$ \\
\hline Brazilin (2) & $4.6 \pm 0.63$ & $16.7 \pm 0.41$ \\
\hline 1a & $18.71 \pm 2.82$ & $(40.87 \pm 3.49)^{* * *}$ \\
\hline $1 b$ & $1.2 \pm 0.02$ & $1.9 \pm 0.31$ \\
\hline $1 \mathrm{c}$ & $1.65 \pm 0.09$ & $3.28 \pm 0.51$ \\
\hline 1d & $(14.14 \pm 5.70)^{*}$ & $13.25 \pm 1.14$ \\
\hline 1e & $(16.37 \pm 3.71)$ & $(11.39 \pm 4.76)$ \\
\hline 1f & $(-7.00 \pm 4.90)$ & $15.50 \pm 2.40$ \\
\hline $1 \mathrm{~g}$ & $4.65 \pm 1.31$ & $13.6 \pm 1.09$ \\
\hline 1h & $(18.61 \pm 6.29)^{*}$ & $(26.76 \pm 6.60)^{*}$ \\
\hline $1 \mathbf{i}$ & $23.94 \pm 5.48$ & $(35.54 \pm 1.71)^{* * *}$ \\
\hline $1 \mathbf{j}$ & $4.35 \pm 0.91$ & $8.37 \pm 0.41$ \\
\hline $1 \mathrm{k}$ & $(33.38 \pm 7.75)^{* *}$ & $8.76 \pm 1.51$ \\
\hline 11 & $16.16 \pm 0.40$ & $11.83 \pm 2.00$ \\
\hline $1 \mathrm{~m}$ & $19.72 \pm 4.44$ & $16.54 \pm 1.70$ \\
\hline 1n & $19.69 \pm 5.82$ & $10.06 \pm 0.60$ \\
\hline 7 & $\mathrm{NT}^{b}$ & $\mathrm{NT}^{b}$ \\
\hline 8 & $1.90 \pm 0.32$ & $(43.71 \pm 2.00)^{* * *}$ \\
\hline 9 & $8.38 \pm 0.02$ & $10.25 \pm 0.14$ \\
\hline 10 & $4.52 \pm 1.21$ & $(35.76 \pm 2.60)^{*}$ \\
\hline $\mathbf{D P I}^{c}$ & $0.7 \pm 0.4$ & \\
\hline $\mathbf{P M S F}^{c}$ & & $130.9 \pm 2.91$ \\
\hline
\end{tabular}

${ }^{a}$ IC50 represents the $50 \%$ inhibitory concentration of the compound. If $50 \%$ inhibition was not reached at any test dose, the percentage of inhibition obtained at a test dose of $10 \mu \mathrm{g} / \mathrm{mL}$ is given in parentheses (Inh \%). Results are presented as mean \pm S.E.M. $(\mathrm{n}=3-5)$.

* $p<0.05$

$* *$

$p<0.01$, and

$* * *$

$p<0.001$ compared with the control value.

${ }^{b}$ Abnormal absorption at OD405 and $550 \mathrm{~nm}$.

${ }^{c}$ DPI and PMSF were used as positive controls. 


\section{Table 3}

Cytotoxic effects of $\mathbf{1}$-analogs.

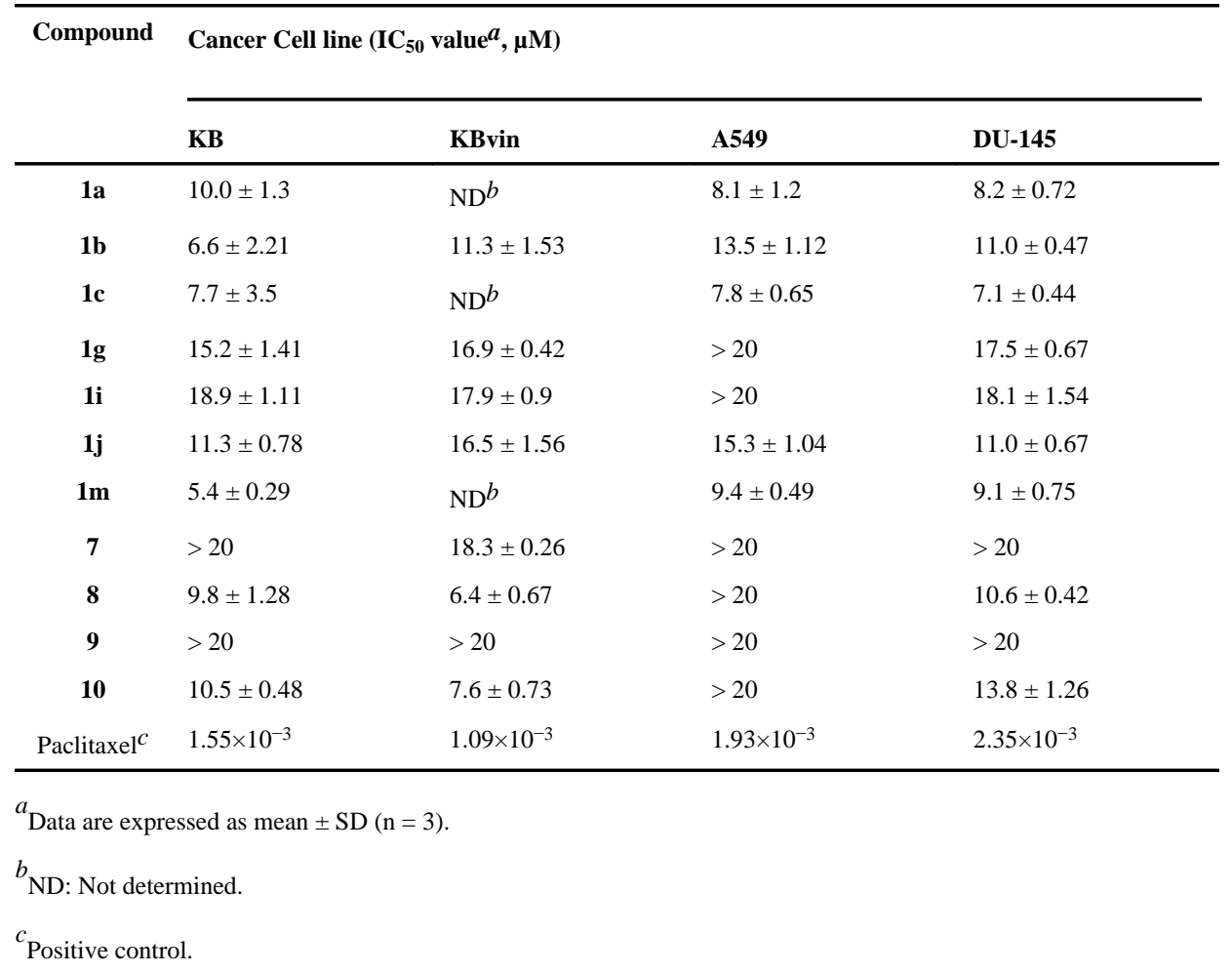

